\title{
Impact of the intumescent formulation of styrene acrylic-based coatings on the fire performance of thin painted red lauan (Parashorea spp.) plywood
}

\author{
Chih-Shen Chuang $\cdot$ Kuang-Chung Tsai $\cdot$ Ming-Kuang Wang $\cdot$ Chun-Han Ko \\ Shiau Ing-Luen
}

Received: 10 July 2008 / Published online: 2 May 2009

(C) Springer-Verlag 2009

\begin{abstract}
Intumescent material with commercial resin, such as styrene acrylic copolymer resin, has been demonstrated to be extremely effective in improving the fire performance of wooden materials used for indoor furnishing. The formulation of the coating is a key to its ability to improve flame retardance. This study investigates the enhancement for painted thin red lauan (Parashorea spp.) plywood. The ability of the material to retard flame arises due to the interactions between the four major components of intumescent formulation: (1) a binder resin (BR), styrene acrylic emulsion resin, (2) a carbonizing substance (CS), pentaerythritol (3) a foam producing substance (FPS), melamine and (4) a dehydrating agent (DA), ammonium polyphosphate. This paper compares the fire performance of the plywood when coated with resin of differing BR/CS ratios (designated as the FRS series) and FPS/DA ratios (designated as the FRD series), by means of a cone calorimeter. These
\end{abstract}

\section{C.-S. Chuang · C.-H. Ko (区)}

School of Forestry and Resource Conservation,

National Taiwan University,

No. 1, Sec. 4, Roosevelt Rd,

106 Taipei, Taiwan

e-mail: chunhank@ntu.edu.tw

K.-C. Tsai

Department of Safety Health and Environmental Engineering, National Kaohsiung First University of Science and Technology, 811 Kaohsiung, Taiwan

M.-K. Wang

Department of Agricultural Chemistry,

National Taiwan University,

106 Taipei, Taiwan

S. Ing-Luen

Department of Forest Products Science,

National Chiayi University,

600 Chiayi, Taiwan intumescent formulations significantly enhanced the fire retardancy of painted plywood, exhibiting lower peak heat release rates, higher expansion of the intumescent layer and longer time to peak heat release rates (PHRR), when compared to plywood panels coated with sole binder resin. However, worse performance was presented when compared with the data for uncoated plywood panels if the intumescent was produced by equal ratio of the four components. Therefore, the formulation of the intumescent is important. Additionally, lower BR contents in the FRS series and lower FPS contents in the FRD series further enhanced flame retardancy. Advanced investigation by IR and ${ }^{31} \mathrm{P}$ NMR demonstrated that lower BR and FPS content extends the survival duration of the phosphor-carbonaceous structure of chars. The findings in this study enhance the state-of-the-art understanding of the effect of the intumescent.

\section{Einfluss von schaumschichtbildenden Beschichtungen auf Styrol-Acryl-Basis auf das Brandverhalten von dünnem Lauansperrholz (Parashorea spp.)}

Zusammenfassung Schaumschichtbildner mit handelsüblichem Harz, wie zum Beispiel Styrol-Acryl Kopolymerharz, haben sich als äußerst effektiv zur Verbesserung des Brandverhaltens von im Innenausbau verwendeten Holzprodukten erwiesen. Entscheidend für die Brandschutzwirkung ist die Rezeptur der Beschichtung. Dies wurde hier am Beispiel von beschichtetem dünnen Lauansperrholz (Parashorea spp.) untersucht. Die flammenhemmende Eigenschaft ist auf das Zusammenwirken der vier Hauptkomponenten von schaumschichtbildenden Beschichtungen zurückzuführen: 1) einem Harzbinder (BR), Styrol-AcrylEmulsionsharz, 2) einer verkohlungswirkenden Substanz (CS) Pentaerythrit, 3) einer Schaum bildenden Substanz 
(FPS) Melamin, und 4) einem Entwässerungsmittel (DA) Ammoniumpolyphosphat. In dieser Studie wird mit Hilfe von Kone-Kalorimeter Messungen das Brandverhalten des Sperrholzes untersucht, das mit Harz mit unterschiedlichen BR/CS-Anteilen (als FRS-Serie bezeichnet) und PFS/DAAnteilen (als FRD-Serie bezeichnet) beschichtet worden ist. Diese schaumschichtbildenden Beschichtungen haben den Feuerwiderstand von beschichtetem Sperrholz signifikant erhöht. Im Vergleich zu nur mit Harzbinder beschichteten Sperrholzplatten ergaben sich dabei geringere Peaks für die Wärmefreisetzungsraten, eine höhere Ausbreitung der schaumschichtbildenden Schicht und eine längere Dauer bis zum Erreichen der maximalen Wärmefreisetzungsrate (PHRR). Brandschutzbeschichtungen mit gleichen Anteilen aller vier Komponenten zeigten im Vergleich zu den unbeschichteten Sperrholzplatten jedoch ein schlechteres Verhalten. Deswegen spielt die Rezeptur der Brandschutzbeschichtung eine wichtige Rolle. Des Weiteren zeigte sich, dass ein niedrigerer BR-Gehalt in den FRS-Serien und ein niedrigerer FPS-Gehalt in den FRD-Serien die Flammenhemmung weiter verbesserten. Untersuchungen mittels IR und ${ }^{31} \mathrm{P}$ NMR ergaben, dass ein niedrigerer BR- und FPSGehalt die Überlebensdauer der Phosphor-Karbonstruktur der verkohlten Schicht verlängert hat. Die Ergebnisse dieser Studie geben einen tieferen Einblick in die Wirkung einer Brandschutzbeschichtung.

\section{Introduction}

Commercial polymers, such as styrene acrylic copolymer resin, are widely used for indoor furnishings and commonly applied to wood-based materials to protect their surface. Wood and wood-based materials are of great importance in residential, commercial and industrial building construction. Due to its chemical constitution, wood is flammable, so employing flame retardants becomes important. Due to an increasing requirement for public safety, flame-retardant treatment of wood-based materials has experienced increased demand (Mitchell 1993, Chuang and Wang 2002). Fire retardants are defined as chemical compounds that modify the pyrolysis mechanisms of the oxidation reaction and subsequently retard the process of combustion (Demir et al. 2005).

The fastest and most convenient way to enhance the fire performance of wood-based materials is to apply fire retardant paints, which are commonly using an intumescent coating on the material surface. Under the heat of the earlier stage of a fire, intumescent paints achieve flame-retardancy by forming a charred layer acting as a physical barrier to deter heat and mass transfer between the gas and the condensed phases (Bourbigot et al. 1996). The charred layers, with low thermal conductivity, then form a carbonaceous layer by cyclisation and cross-linking with phosphate ester (Horrocks and Price 2001).

Generally, intumescent formulations contain four major components: (1) binder resin (BR), (2) a carbonizing substance (CS) to form the carbonized layer such as polyols, (3) a foam producing substance (FPS) to release inert gases $\mathrm{NH}_{3}, \mathrm{CO}_{2}$ and $\mathrm{H}_{2} \mathrm{O}$ as well as to support intumescent action and char formation in order to further retard heat and mass transfer and (4) a dehydrating agent (DA) to lower the decomposition temperature and accelerate the formation of a carbonized layer, such as ammonium phosphate, boric acid and borax (Gao et al. 2006). The impact of intumescent formulation on the fire performance of coated plywood has been demonstrated (Chuang et al. 2008). However, the intumescent mechanisms are rarely elucidated by investigating the evolution of the char chemical structure under heat.

In this study, different formulations using four major components were systematically investigated to provide a fundamental understanding of the influence of intumescent gradients. The components used were: (1) styrene acrylic copolymer emulsion resin as a binder resin (BR), (2) pentaerythritol as a carbonizing substance (CS), (3) melamine as a foam producing substance (FPS) and (4) ammonium polyphosphate as a dehydrating agent (DA). A cone calorimeter was used to investigate the change in fire performance of plywood painted with different formulations. The differing heating times of the fire-retardant paint chars were collected. Their structural features were analyzed using Fourier-transformed infrared spectroscopy and ${ }^{31} \mathrm{P}$ solid-state nuclear magnetic resonance spectroscopy. Relationships between the char chemical structure and fire performance were also investigated.

\section{Materials and methods}

\subsection{Materials}

In this study, a red lauan (Parashorea spp.) plywood panel was used as a substrate, with dimensions of $300 \mathrm{~mm}(\mathrm{~L}) \times$ $300 \mathrm{~mm}(\mathrm{~W}) \times 4 \mathrm{~mm}(\mathrm{~T})$. The intumescent fire retardant (IFR) paint contained a commercial styrene acrylic copolymer emulsion resin; the BR consisted of methylmethacrylate (MMA) 10\%, butylacrylate (BA) 16\% and styrene monomer (SM) 15\% (Yeou Shuenn Products Co., Ltd., Kaohsiung, Taiwan), with $2000 \mathrm{cps}$ viscosity and a solid content of $48 \%$. The pentaerythritol and melamine were purchased from Acros Organics (Phillipsburg, NJ, USA). Ammonia polyphosphate (APP) was purchased from U-Way C.E.T. Co., Taipei, Taiwan. The degree of polymerization $(n)$ of ammonia polyphosphate in this study was approximately 1000 and the decomposition temperature was $215^{\circ} \mathrm{C}$. 


\subsection{Sample preparations}

The required weight of each of the four major components were combined and stirred at $600 \mathrm{rpm}$ for $4 \mathrm{~h}$. Three different groups were investigated: the control, the FRS, and the FRD series. The control series included the following scenarios: (1) a plywood panel coated with styrene acrylic copolymer emulsion resin (CSP) and (2) a plywood panel coated with fire retardant formulation 1 (FR). The effect of adding only the intumescent formulation upon the fire performance of painted plywood was consequently evaluated. The FRS series had identical solid weight ratio (w/w) of FPS and DA with changing ratios of BR and CS to investigate char forming capability. With constant BR/CS weight ratio, the FRD series assessed the interaction of the foamproducing substance (FPS) and the dehydrating agent (DA) by changing FPS/DA ratios. The ratio of formulation was in accordance with Chuang et al. (2008).

The fire-retardant paint was spread on the surface of the plywood panel using a brush and then air-dried. The solid content of fire-retardant paint was approximately $60 \%$ during painting. The solid coating weight was $360 \mathrm{~g} \mathrm{~m}^{-2}$ (i.e. each plywood panel was coated with a total of $32.4 \mathrm{~g}$ of paint after three equal coatings). Prior to flammability testing, air-dried specimens (i.e. coated plywood panels) were heated at $45^{\circ} \mathrm{C}$ in an oven for $48 \mathrm{~h}$, then the cooled specimens were placed in a desiccator for $24 \mathrm{~h}$. According to CNS 6532 (1993), the moisture content for all specimens must be equal. Since the relative humidity of Taiwan is around $60-80 \%$, preconditioning is necessary. The preconditioning procedure for moisture content control is specified in ASTM E 1354-99.

\subsection{Flammability tests by cone calorimeter}

A cone calorimeter (Fire Testing Technology Ltd, East Grinstead, UK) was employed to evaluate the efficiency of the fire retardant, as specified using the ASTM E 1354 method (1999). Specimens were placed in horizontal orientation with an external igniter, and the flux of the cone heater was set at $50 \mathrm{~kW} \mathrm{~m}^{-2}$. This scenario simulated a heating environment where a specimen is exposed to a fully developed fire. The total test time was $1200 \mathrm{~s}$, which is often regarded as the time people can evacuate, and all tests were conducted in triplicate. The following fire properties of the materials were determined: average heat release rate $\left[\mathrm{HRR}_{\mathrm{av}}\right.$ $\left(\mathrm{kW} \mathrm{m}^{-2}\right)$ ] (within $1200 \mathrm{~s}$ ); peak heat release rate [PHRR $\left(\mathrm{kW} \mathrm{m}^{-2}\right)$ ]; total heat release [THR $\left(\mathrm{MJ} \mathrm{m}^{-2}\right)$ ]; height of the intumescent layer (mm); time to ignition [Tig (s)] and time to PHRR (s). The PHRR and HRR $\mathrm{Hv}_{\mathrm{av}}$ values correspond to the acceleration of the thermal degradation of the materials, which is related to the spread of fire. Total heat release (THR) indicates the total heat capacity during the process of material combustion. The THR with a duration of 200, 300 and $400 \mathrm{~s}$ were then integrated from the heat release rate profiles for additional analysis. The height of the intumescent layer was evaluated to investigate the ability of the intumescent paint to retard fire. PHRR was used to evaluate fire retardance of the intumescent char. Conclusively longer time to initiate a fire (Tig) and lower consequent heat release information (PHRR, HRR $_{\mathrm{av}}$ and THR) are the criteria of good fire performance.

\subsection{Fourier-transform Infrared (FT-IR) analysis}

The char of FRS and FRD samples, at $50 \mathrm{~kW} \mathrm{~m}^{-2}$ heat flux for 60,100 , and $150 \mathrm{~s}$, were collected, grinded and pelletized with $\mathrm{KBr}$ powder in 1:300 ratio $(\mathrm{mg} / \mathrm{mg})$. Then the pellets were scanned in the range of $4000-500 \mathrm{~cm}^{-1}$ and as-synthesized manganese oxide samples were recorded on a Nicolet 380 spectrophotometer (Thermo Scientific, Inc., Waltham, MA, USA). The varied heating time of different compositions can be used to evaluate the functional groups of fire retardant chemical reaction.

\section{$2.5^{31} \mathrm{P}$ solid state nuclear magnetic resonance spectroscopy (NMR) analysis}

In order to analyze the products of degradation of the intumescent systems over different heating time, heat treatments were carried out by a cone calorimeter under $50 \mathrm{~kW} \mathrm{~m}^{-2}$ and a heating time of 60,100 , and $150 \mathrm{~s}$. The solid prepared residues were then analyzed using solid-state NMR. High resolution ${ }^{31} \mathrm{P}$ NMR spectroscopies of the solids were performed using a Bruker DSX 400WB NMR instrument. Bruker probe heads equipped with a magic-angle spinning (MAS) assembly were used. The measurements were performed at $40.5 \mathrm{MHz}(2.35 \mathrm{~T})$ using MAS $(5 \mathrm{kHz})$ with or without ${ }^{1} \mathrm{H}$ dipolar decoupling. A repetition time of $450 \mathrm{~s}$ was used for all samples. $\mathrm{H}_{3} \mathrm{PO}_{4}$ in aqueous solution (85\%) was used as reference, and prior to starting a new experiment, the chemical shift reference was always verified within $\pm 0.2 \mathrm{ppm}$.

\subsection{Statistical analysis}

SAS Institute Inc. (1994) software was employed for statistical analysis (SAS Institute Inc., Cary, NC, USA). The statistical analysis of THR values were used to evaluate the correlation between different components and combustion time (i.e., 200, 300, 400 s). A linear regression analysis was applied and the goodness-of-fit was evaluated using $r^{2}$ (determination coefficient), level of significance ( $P$-value), and standard error (SE). The comparison of the different amounts of BR and FPS, correlated with combustion time were performed using the least significant difference (LSD). 
The LSD values were calculated using SE and t test at appropriate degrees of freedom and $95 \%$ confidence levels.

\section{Results and discussion}

\subsection{The cone calorimeter test results of different coatings on plywood panels}

Figures 1, 2 and 3 show the heat release rate (HRR) curves of all specimens in the cone calorimeter tests. Table 1 lists the data of the Tig, $H_{R R}$ av PHRR, THR, the maximum thickness of char layer and time to PHRR. Obviously the first peak is attributed to the fire-retardant paint, while the second accounted from plywood. The PHRR and time to PHRR data were expressed as two items, performing the peak values of the two stages described above. The PHRR was the most significant parameter when identifying the enhancement of flame-retardancy for the samples. Comparisons of PHRR, the average of heat release rate $\left(\mathrm{HRR}_{\mathrm{av}}\right)$, THR and time to PHRR also assisted, to a lesser degree, in

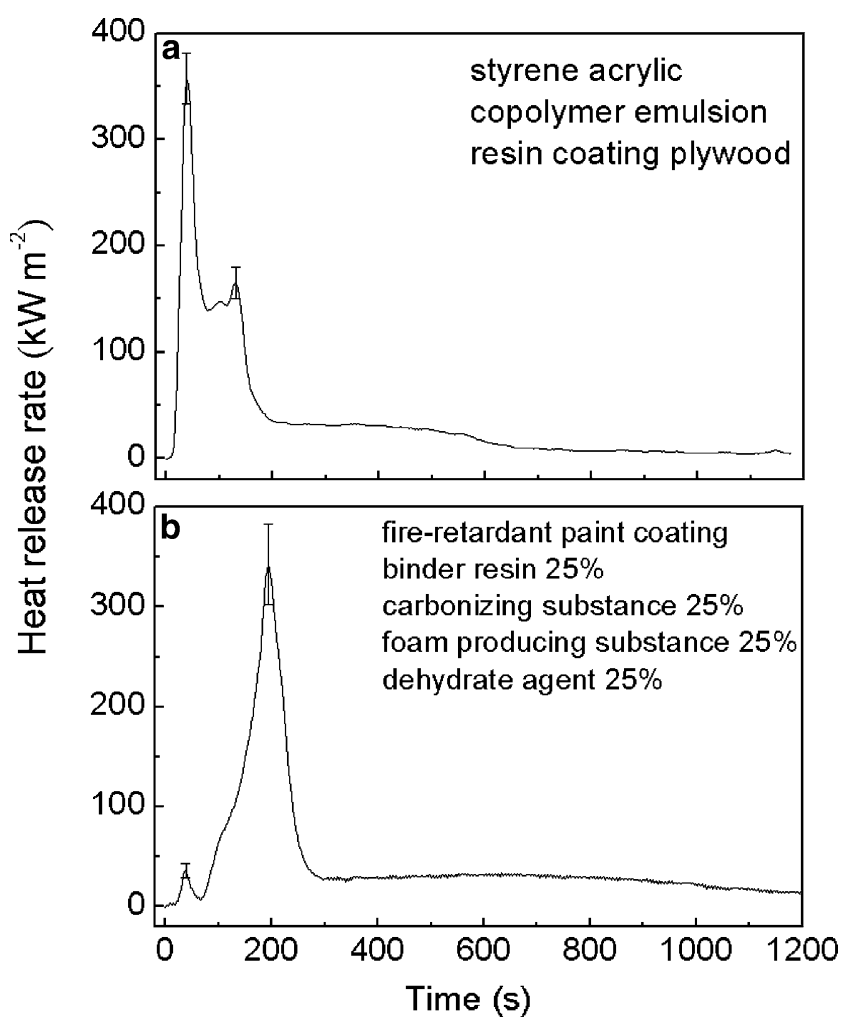

Fig. 1 Heat release profiles for different coatings on $4 \mathrm{~mm}$ plywood panel of a CSP, and b FR (with BR/CS/FPS/DA ratio of 25/25/25/25) samples under cone calorimeter tests

Abb. 1 Wärmefreisetzungsverlauf für unterschiedlich beschichtete, $4 \mathrm{~mm}$ dicke Sperrholzplatten. a Kopolymer-Emulsion (CSP) und b Beschichtungen, mit gleichen Komponentenanteilen (FR mit BR/ CS/FPS/DA von 25/25/25/25) mittels Kone-Kalorimeter-Prüfungen the evaluation of the flame-retardancy demonstrated by the various intumescent formulations for the samples (Table 1).

The peak heat release rate (PHRR) of uncoated plywood (UP) was $249 \mathrm{~kW} \mathrm{~m}^{-2}$ and the total heat release (THR) was $58 \mathrm{MJ} \mathrm{m}^{-2}$, the time to PHRR and Tig was $207 \mathrm{~s}$ and $81 \mathrm{~s}$, respectively (Chuang et al. 2008). After coating with only styrene acrylic copolymer emulsion resin (CSP), the first stage PHRR raised to $358 \mathrm{~kW} \mathrm{~m}^{-2}$, and THR reduced to $42 \mathrm{MJ} \mathrm{m}^{-2}$. Moreover, time to ignition (Tig) decreased to $6 \mathrm{~s}$. The second stage PHRR was $165 \mathrm{~kW} \mathrm{~m}^{-2}$ as shown in Fig. 1a and Table 1. The time to PHRR of the first and

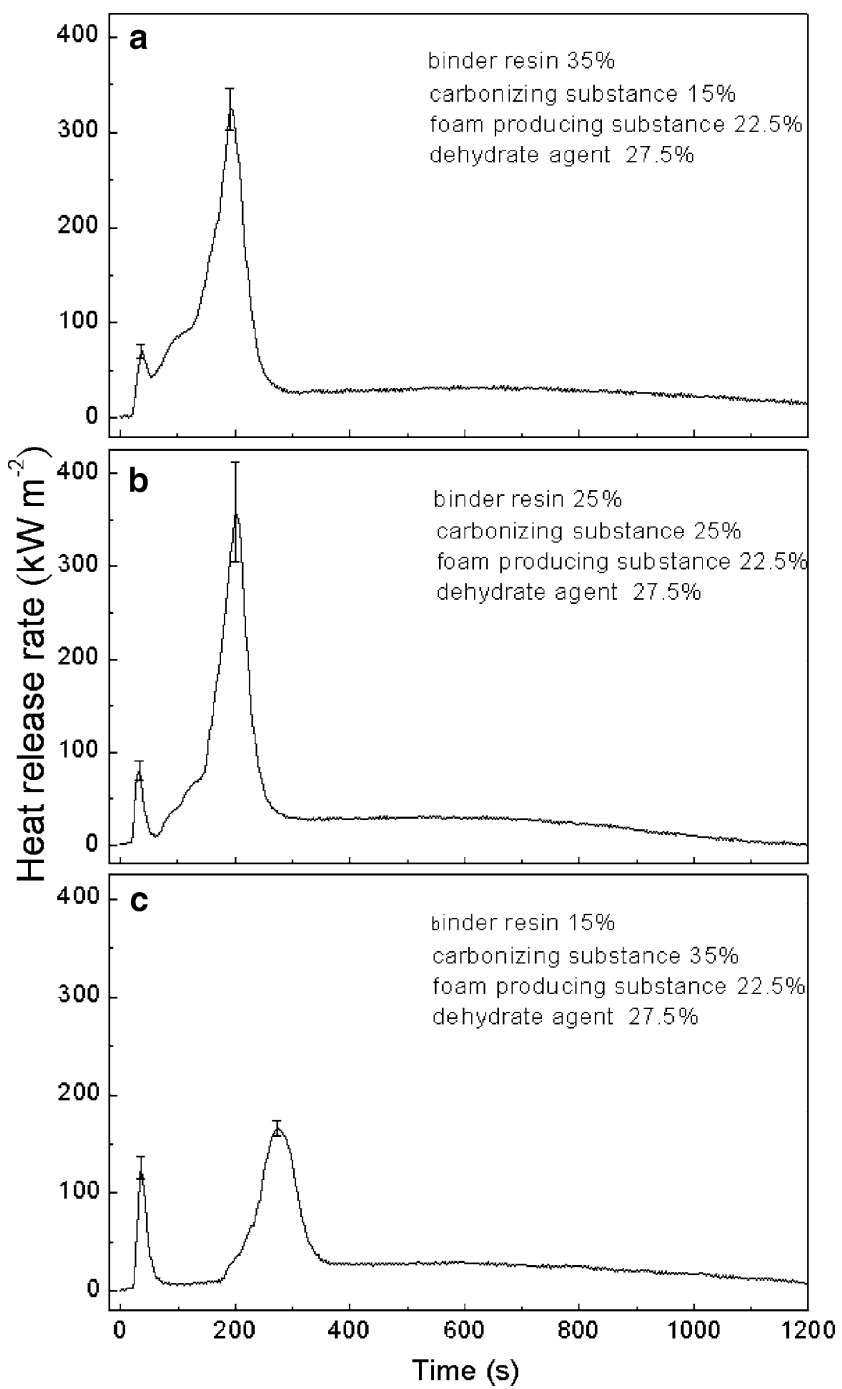

Fig. 2 Heat release profiles for different coatings on $4 \mathrm{~mm}$ plywood panel combustion of a FRS1 (with BR/CS/FPS/DA ratio of 35/15/22.5/27.5), b FRS2 (with BR/CS/FPS/DA ratio of 25/25/22.5/ 27.5), and c FRS3 (with BR/CS/FPS/DA ratio of 15/35/22.5/27.5) samples under cone calorimeter tests

Abb. 2 Wärmefreisetzungsverlauf unterschiedlich beschichteter, $4 \mathrm{~mm}$ dicker Sperrholzplatten. a FRS1-Serie (mit BR/CS/FPS/DA Verhältnis von 35/15/22,5/27,5), b FRS2-Serie (mit BR/CS/FPS/DA Verhältnis von 25/25/22,5/27,5), und c FRS3-Serie (mit BR/CS/FPS/DA Verhältnis von 15/35/22,5/27,5) mittels Kone-Kalorimeter-Prüfungen 


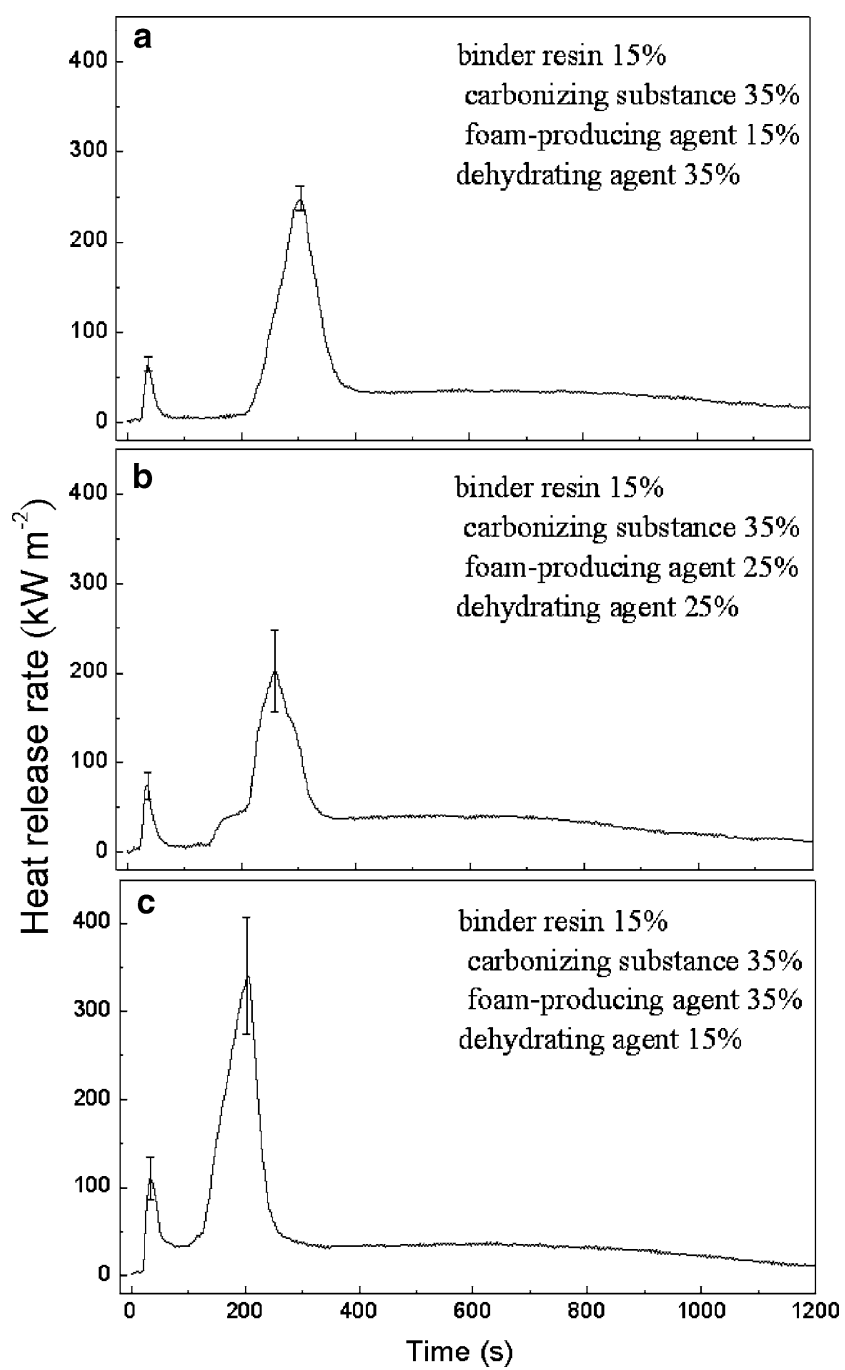

Fig. 3 Heat release profiles for different coatings on $4 \mathrm{~mm}$ plywood panel combustion of a FRD1 (with BR/CS/FPS/DA ratio of 15/35/15/35), b FRD2 (with BR/CS/FPS/DA ratio of 15/35/25/25), and c FRD3 (with BR/CS/FPS/DA ratio of 15/35/35/15) samples under cone calorimeter tests

Abb. 3 Wärmefreisetzungsverlauf unterschiedlich beschichteter, $4 \mathrm{~mm}$ dicker Sperrholzplatten. a FRS1-Serie (mit BR/CS/FPS/DA Verhältnis von 15/35/15/35), b FRD2-Serie (mit BR/CS/FPS/DA-Verhältnis von 15/35/25/25), und c FRD3-Serie (mit BR/CS/FPS/DA-Verhältnis von 15/35/35/15) mittels Kone-Kalorimeter-Prüfungen second stages was 39 and $132 \mathrm{~s}$, respectively. The CSP displayed a shorter Tig and time to PHRR indicating that the sole styrene acrylic copolymer emulsion resin coating did not provide fire retardancy to the plywood; in fact it increased the flame spread on the painted plywood surface. After $700 \mathrm{~s}$ (Fig. 1a) there was no heat release rate observed, indicating that the plywood had almost completely burned away. Wladyka-Przbylak and Kozlowski (1999) reported similar observations, demonstrating that the PHRR of wood coated with urea formaldehyde as a binder reagent was higher than uncoated wood.

Additionally, the cone calorimeter tests were conducted to evaluate the flame retardancy of plywood coated with intumescent which consisted of an equal composition of the four components (case FR). Results, as shown in Fig. 1b and Table 1, again demonstrated two peaks of HRR. The first peak heat release indicated char forming by intumescent action, and char decomposition, followed by plywood combustion was demonstrated at the second peak heat release. Intervals between the first and the second PHRR indicate the thermal durability of the char. Compared with the data of CSP, a much lower first stage PHRR value (i.e. $36 \mathrm{~kW} \mathrm{~m}^{-2}$ ) as well as longer time intervals to the occurrence of second stage PHRR (195 s) were presented, validating the use of all four components. However, compared with the data of UP, not only the time to first stage ignition (Tig) was shorter due to the burning of the intumescent layer, but occurrence of the second stage PHRR was earlier. In addition, the value of PHRR increased. Clearly worse fire performance was presented even with the formation of char layer. Similar observation was made by Chuang et al. (2008). The comparison demonstrated that the formulation of the four components is important!

\subsection{Enhancement of flame-retardance using formulations with different BR contents}

Due to the importance of the formulation of the four components, tests for the FRS series were employed to study the impact of altering the ratio of binder resin (BR) and the carbonizing substance (CS) on the fire retardance of
Table 1 Results from cone calorimeter evaluation of plywood coated with various formulations

Tabelle 1 Ergebnisse der Kone-Kalorimeter-Messungen an mit unterschiedlichen Rezepturen beschichtetem Sperrholz

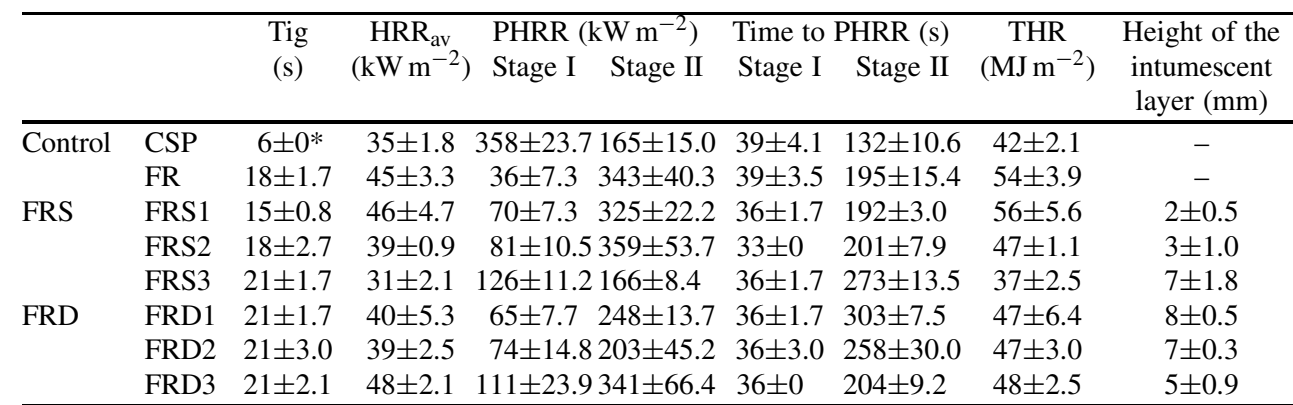

$* \pm$ : standard deviation $(n=3)$ 
the painted plywood, setting the solid weight ratio of FPS and DA at 22.5 and $27.5 \%$, respectively. Comparison of the FRS1 and FRS3 HRR $_{\mathrm{av}}$ values show that FRS3 was much lower than FRS1 within 1200 s. The second stage of PHRR and THR displayed the same trend. On the other hand, FRS3 shows great swelling of the intumescent layer (Table 1 and Fig. 2). In demonstrating lower heat release rates values, larger intervals between peak heat release occurrence, a higher intumescent layer and a longer time to peak heat release, the flame-retardancy was ranked as FRS3 > FRS2 > FRS1. Excessive binder resin provided more combustible material and contributed to a higher PHRR and lowered thermal durability of the FRS1 char. The higher BR content also decreased the height of the intumescent layer. Hence, more CS and less BR content improved the fire performance and showed better protection of the underlying material (i.e. plywood). Among the FRS series, the optimal $\mathrm{BR} / \mathrm{CS}$ formulation was obtained at a weight ratio of $15 / 35$, designated as FRS3.

\subsection{Enhancement of flame-retardancy using formulations with different FPS contents}

To further investigate the interaction between the foam producing substance (FPS) and dehydrating agents (DA), the FRD series was conducted by changing FPS/DA weight ratios for FRD1, FRD2 and FRD3 samples to 35/15, 25/25 and $15 / 35$, respectively. The results of the cone calorimeter tests summarized in Table 1 showed that increasing the FPS contents of intumescent formulation accelerated the combustion of painted plywood and raised the peak heat release rates. The height of the intumescent layer also reduced from $8 \mathrm{~mm}$ to $5 \mathrm{~mm}$, and the time to the second PHRR decreased to approximately $100 \mathrm{~s}$. Shorter intervals between the two heat release rates for FRD3 suggested that excessive amounts of FPS (i.e., melamine) might form a thinner char and reduce the thermal durability of the chars. The role played by the foam producing substance in the intumescent formulations was to generate incombustible gases to support the intumescent layer and to block further air access (WladykaPrzbylak and Kozlowski 1999). However, an increase in the incombustible gas generated by excessive melamine failed to improve the flame-retardancy of FRD3. On the other hand, increasing dehydrating agents, such as ammonium polyphosphate may increase the flame retardancy of painted plywood. Under heat, esterification reactions would occur between carbonizing substances (i.e. polyols) and dehydrating agents (i.e. phosphorous compounds). Furthermore, chars with a phosphor-carbonaceous structure would be formed (Horrocks and Price 2001). The HRR av and THR values of FRD1 and FRD2 were similar, thus the time intervals to reach the first and second stage of peak heat release was a significant parameter used when establishing the fire performance of FRD1 (i.e. 303 s) and FRD2 (i.e. 258 s). The FRD1 sample demonstrated better flame retardancy in the cone calorimeter tests through longer time between two peak heat releases. The longer time intervals to reach the PHRR value in the FRD1 formulation at 15\% FPS and 35\% DA demonstrated superior plywood protection. Hence, the flame-retardancy was ranked to be FRD1 > FRD2 > FRD3.

\subsection{Fourier-transform infrared analysis (FT-IR) of FRS and FRD series}

The reactions of the FRS and FRD series were further evaluated. The FTIR analysis of the chars heated for 60, 100 and $150 \mathrm{~s}$ demonstrated the different functional groups after combustion (Fig. 4). In the FRS series, the P-O-P of IR bending vibration was observed to be $883-902 \mathrm{~cm}^{-1}$. The additional broad bands of about $948-972 \mathrm{~cm}^{-1}$ were assigned to modes of symmetrical vibration of $\mathrm{PO}_{2}$ and $\mathrm{PO}_{3}$ (Le Bras and Bourbigot 1999). The P-O-C bonds of IR vibration modes were observed at $1076-1080 \mathrm{~cm}^{-1}$ which was due to "phosphate-carbon" complexes and/or P-O in a vitreous structure (Le Bras and Bourbigot 1999). The P$\mathrm{O}-\mathrm{C}$ bond was formed by alcoholysis of the polyphosphate chain (Camino et al. 1985). The $\mathrm{P}=\mathrm{O}$ of the IR vibration mode was found at $1107-1168 \mathrm{~cm}^{-1}$. At $60 \mathrm{~s}$, these IR absorption bands indicated that the interaction between phosphoric acid and alcohol had resulted in a phosphorcarbonaceous structure (Fig. 4); this was the main product and its formation dictated the flame retardancy. At $100 \mathrm{~s}$,
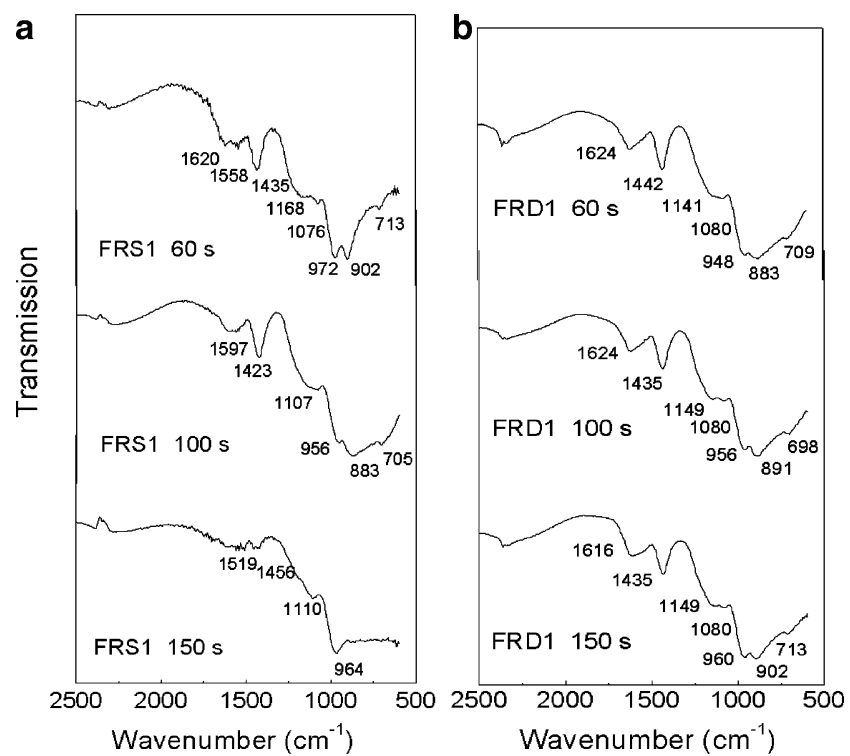

Fig. 4 The FTIR spectra at different heating time: a FRS1 (with BR/CS/FPS/DA ratio of 35/15/22.5/27.5), b FRD1 (with BR/CS/FPS/ DA ratio of $15 / 35 / 15 / 35$ )

Abb. 4 FTIR-Spektren bei unterschiedlicher Prüfdauer: a FRS1-Serie (mit BR/CS/FPS/DA Verhältnis von 35/15/22,5/27,5), b FRD1-Serie (mit BR/CS/FPS/DA Verhältnis von 15/35/15/35) 
there was no P-O-C IR absorption band (i.e. $1076 \mathrm{~cm}^{-1}$ ) in the IR spectra of the FRS1 (Fig. 4). The result was attributed to the degradation of the phosphor-carbonaceous structure. At $150 \mathrm{~s}$, there was no P-O-C IR absorption band in the IR spectra of FRS2, the P-O-P of IR bending vibration had also disappeared in FRS1.

Compared to the cone calorimeter experiment, the plywood coated with FRS1 burned from $54 \mathrm{~s}$ to $318 \mathrm{~s}$. The time to second PHRR was $192 \mathrm{~s}$, thus the phosphor-carbonaceous char was degraded and the plywood was exposed to the heat at $150 \mathrm{~s}$. The FRD series had the same trend in phosphorcarbonaceous char transformation. According to the cone calorimeter tests, the FRD1 had the longest interval time to second PHRR. The FRD1 IR spectra also demonstrate the entire phosphor-carbonaceous at 60, 100, and $150 \mathrm{~s}$ (Fig. 4). At $150 \mathrm{~s}$, there was no observable P-O-P and P-O-C bond in FRD3. Comparing these results to the cone calorimeter experiment, the plywood coated with FRD3 compositions was exposed to heat combustion and demonstrated degradation of the phosphor-carbonaceous char. On the other hand, the IR absorption bands were shown to be $\mathrm{NH}_{4}^{+}$and symmetrical deformation of $\mathrm{CH}_{2}, \mathrm{CH}_{3}$ at 1423-1442 and 1519$1624 \mathrm{~cm}^{-1}$, respectively (Le Bras and Bourbigot 1999), which derived from the melamine. The flame retardancy can be evaluated by the degree of esterification, with faster esterification corresponding to a more flame retardant char (Baljinder and Horrocks 1996, Lindsay et al. 2000, Drevelle et al. 2004, Bourbigot et al. 2004). Consistent trends, demonstrated by cone calorimeter tests and FTIR analysis, indicated that the lower BR contents resulted in a more durable phosphor-carbonaceous char structure. Lower FPS contents also behaved in the same manner. Thus, different proportions of the four major compounds had significantly impacted the fire performance of painted thin plywood.

\subsection{Solid state ${ }^{31} \mathrm{P}$ NMR analysis of FRS and FRD series}

FTIR suggests the formation of the phosphocarbonaceous structure. ${ }^{31} \mathrm{P}$ NMR has been used to monitor the thermal degradation of APP in the mixtures with the other three compounds. In Fig. $5,{ }^{31} \mathrm{P}$ NMR spectra of the FRS and FRD series after being heated for 60,100 and $150 \mathrm{~s}$ at $50 \mathrm{~kW} \mathrm{~m}^{-2}$ are shown. Using previous studies' assignments, the characteristic bands of APP ( -22 and $-24 \mathrm{ppm}$ ) were observed (Le Bras and Bourbigot 1999, Bourbigot et al. 2000).

All the $60 \mathrm{~s}$ spectra showed a band centred at $0 \mathrm{ppm}$ which can be assigned to the orthophosphate group linked to aliphatic groups and/or othorphosphoric acid (Duncan and Douglass 1984). Furthermore, all the $60 \mathrm{~s}$ spectra also had an additional band observed at $-11 \mathrm{ppm}$ assigned to pyrophosphate species and/or to diphenyl- or triphenylothorphosphate groups (Bourbigot et al. 1996). The bands shown at $0 \mathrm{ppm}$ and $-11 \mathrm{ppm}$ indicated that the painted plywood
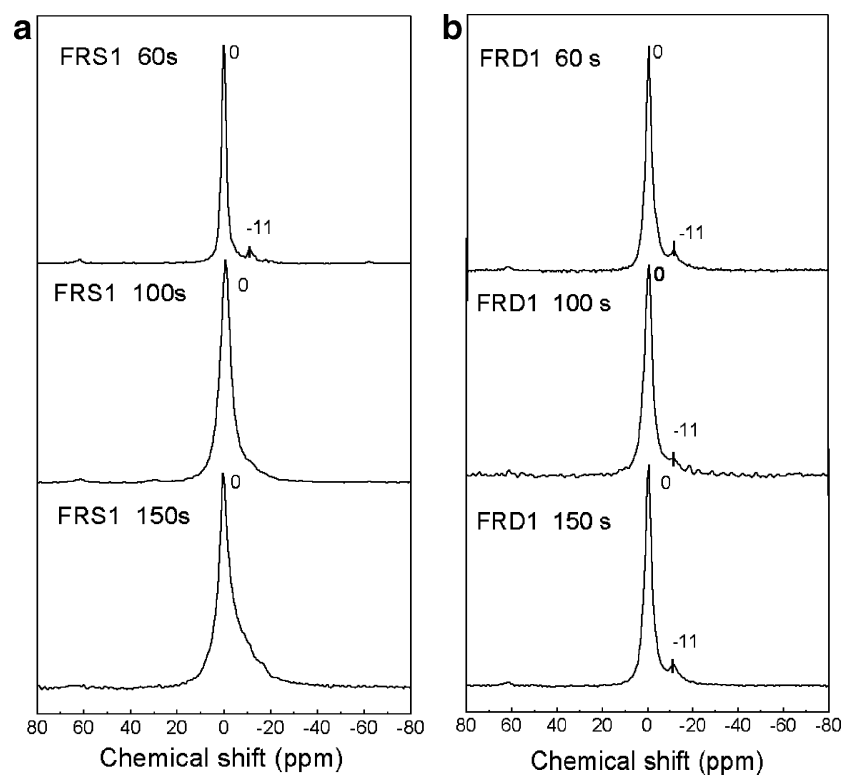

Fig. 5 The ${ }^{31} \mathrm{P}$ NMR spectra at different heating time: a FRS1 (with BR/CS/FPS/DA ratio of 35/15/22.5/27.5), b FRD1 (with BR/CS/FPS/DA ratio of 15/35/15/35)

Abb. $5{ }^{31}$ P NMR Spektren bei unterschiedlicher Prüfdauer. a FRS1Serie (mit BR/CS/FPS/DA Verhältnis von 35/15/22,5/27,5), b FRD1Serie (mit BR/CS/FPS/DA Verhältnis von 15/35/15/35)

was protected by chars with a phosphor-carbonaceous structure. The above findings are consistent with the results of the cone calorimeter tests and FTIR analysis. Under this condition, the intumescent shield can limit oxygen diffusion to the substrate. In FRS1, the band which was assigned to pyrophosphate species $(-11 \mathrm{ppm})$ had disappeared after $100 \mathrm{~s}$ of heating. Using the results of the FRS1 FTIR spectrum and cone calorimeter tests, a degradation of the phosphor-carbonaceous structure is indicated (Fig. 5). At $150 \mathrm{~s}$, the FRS2 and FRD3 also demonstrated the same trend to degradation of the phosphocarbonaceous structure. The orthophosphate $(0 \mathrm{ppm})$ and pyrophosphate $(-11 \mathrm{ppm})$ were observed in FRS3, FRD1 and FRD2 at 60, 100 and $150 \mathrm{~s}$. The above results indicated that the intumescent layers could sustain and protect painted plywood after $150 \mathrm{~s}$. This is supported by the superior cone calorimeter test results of FRS3, FRD1 and FRD2 formulations.

\subsection{Statistical analysis}

The FRS and FRD series were evaluated using the cone calorimeter. All fire retardant painted plywood samples demonstrated two stages of peak heat releases. The first stage PHRR was char forming from the fire retardant formulation to protect the underlying plywood panel, and the second stage PHRR was char decomposition and the burning of plywood. In order to investigate the impact of intumescent formulation on flame retardancy, THR values 
Table 2 Statistical analysis between THR values at 200, 300, and $400 \mathrm{~s}$ and binder resin (BR) contents of FRS series and foam producing substance (FPS) contents of FRD series

Tabelle 2 Statistische Analyse der gesamten Wärmefreisetzungsrate (THR) nach 200, 300 und $400 \mathrm{~s}$ bei den FRS-Serien (Harzbindergehalt BR) und den FRD-Serien (Gehalt an schaumschichtbildenden Substanzen FPS)

\begin{tabular}{|c|c|c|c|}
\hline & $200 \mathrm{~s}$ & $\begin{array}{l}300 \mathrm{~s} \\
r^{2}\end{array}$ & $400 \mathrm{~s}$ \\
\hline FRS & 0.88 & 0.84 & 0.84 \\
\hline \multirow[t]{2}{*}{ FRD } & 0.79 & 0.89 & 0.76 \\
\hline & \multicolumn{3}{|c|}{$P$} \\
\hline FRS & $7.1 \times 10^{-6}$ & $2.5 \times 10^{-5}$ & $3.1 \times 10^{-5}$ \\
\hline \multirow[t]{2}{*}{ FRD } & $1.2 \times 10^{-4}$ & $3.4 \times 10^{-6}$ & $9.7 \times 10^{-4}$ \\
\hline & \multicolumn{3}{|c|}{ SE } \\
\hline FRS & 3.1 & 3.1 & 2.8 \\
\hline FRD & 4.3 & 2.8 & 3.2 \\
\hline
\end{tabular}

of different heating durations were correlated with binding resin contents in the FRS series and with foam producing substance contents in the FRD series. Table 2 summarizes the values of statistical parameters $\left(r^{2}, P\right.$ and SE) for both series. The determination coefficient $\left(r^{2}\right)$ was $0.88,0.84$ and 0.84 for the THR values of the FRS series, indicating good correction between the total heat release (THR) and the BR contents. The THR decreases with decreasing concentration of styrene acrylic copolymer emulsion resin (i.e., BR) in the FRS series. On the other hand, the THR decreases with decreasing melamine (i.e., FPS) content in the FRD series. The determination coefficient $\left(r^{2}\right)$ values were $0.79,0.89$ and 0.76 in the FRD series. The THR value was clearly affected by the FPS contents in this series. Respective THR values decreased in the earlier stage of combustion. It should be noted that the normalized $r^{2}$ value is an effective criterion for evaluating BR and FPS content, since it is definitely related to the formulation of each series. In particular, the trends of SE and $P$ values for both the FRS and FRD series were consistent in the earlier stage of combustion. The above analysis indicates that the intumescent formulation controls the THR values in the early stages of combustion and improved the flame-retardance of painted plywood.

\section{Conclusion}

The fire performance of painted thin red lauan plywood can be changed after coating an intumescent with different concentrations of the four major compounds. According to the data of the cone calorimeter tests, the formulations of FRS3 (with BR/CS/FPS/DA ratio of 15/35/22.5/27.5), FRD1 (with BR/CS/FPS/DA ratio of $15 / 35 / 15 / 35$ ) and FRD2 (with BR/CS/FPS/DA ratio of 15/35/25/25) displayed superior flame-retardance. Additionally, results from THR statistics, PHRR analysis, time to PHRR and the height of the intumescent layer demonstrated that the FRD1 formulation was better than both the FRD2 and FRS3 formulations. Moreover, by the FTIR and ${ }^{31} \mathrm{P}$ NMR analysis, lower BR and FPS contents facilitate the extension of phosphorcarbonaceous structures and promote the fire performance. After understanding the mechanism, the fire performance of plywood with intumescent coating can be enhanced furthermore.

Acknowledgement Financial support (NSC 94-2212-E-327-010, 952622-E-327-008-CC3, and 95-2622-B-002-003-CC3) from National Science Council, Taiwan is acknowledged.

\section{References}

ASTM standard E1354-99 (1999) Standard Test Method for Heat and Visible Smoke Release Rates for Materials and Products Using an Oxygen Consumption Calorimeter. American Society for Testing and Materials, West Conshohoken, PA

Baljinder KK, Horrocks AR (1996) Complex char formation in flame-retarded fire-intumescent combinations-II. thermal analytical studies. Polym Degrad Stabil 54:289-303

Bourbigot S, Le Bras M, Delobel R, Amourex JP (1996) Synergistic effect of zeolite in an intumescent process: Study of the carbonaceous structures using solid-state NMR. J Chem Soc Faraday Trans 92:149-158

Bourbigot S, Le Bras M, Dabrowski F, Gilman JW, Kashiwagi T (2000) PA-6 clay nanocomposite hybrid as char forming agent in intumescent formulations. Fire Mater 24:201-208

Bourbigot S, Le Bras M, Duquesne S, Rochery M (2004) Recent advances for intumescent polymers. Macromol Mater Eng 289:499-511

Camino G, Costa L, Trossarelli L (1985) Study of the mechanism of intumescence in fire retardant polymers: Part VI - mechanism of ester formation in ammonium polyphosphate-pentaerythritol mixtures. Polym Degrad Stabil 12:213-228

Chinese National Standard CNS 6532 (1993) Method of test for the fire-resistibility of internal decorative material of building. National Standard Bureau, Taipei, Taiwan

Chuang CS, Tsai KC, Wang MK, Ou CC, Ko CH (2008) Effects of intumescent formulation for acrylic-based coating on flameretardancy of painted red lauan (Parashorea spp.) thin plywood. Wood Sci Technol 42:593-607

Chuang HB, Wang SY (2002) Effects of retention and distribution of fire retardant chemical on performance of fire retardant treated China fir (Cunninghamia lanceolata) wood. Holzforschung 56: 209-214

Demir H, Arkis E, Balköse D, Ülkü S (2005) Synergistic effect of natural zeolites on flame retardant additives. Polym Degrad Stabil 89:478-483

Drevelle C, Duquesne S, Le Bras M, Lefebvre J, Delobel R, Castrovinci A, Magniez C, Vouters M (2004) Influence of ammonium polyphosphate on the mechanism of thermal degradation of an acrylic binder resin. J Appl Polym Sci 94:717-729

Duncan TM, Douglass DC (1984) On the 31P chemical shift anisotropy in condensed phosphates. Chem Phys 87:339-349

Gao M, Sun CY, Wang CX (2006) Thermal degradation of wood treated with flame retardants. J Therm Anal Calorim 85: $765-769$ 
Horrocks AR, Price D (2001) Fire retardant materials. Woodhead Publishing Limited, Abington, Cambridge, pp 1-30

Lindsay CI, Hill SB, Hearn M, Manton G, Everall N, Bunn A, Heron J, Fletcher I (2000) Mechanisms of action of phosphorus based flame retardants in acrylic polymers. Polym Intell 49:1183-1192

Le Bras M, Bourbigot M (1999) Comprehensive study of the degradation of an intumescent EVA-based material during combustion. J Mater Sci 34:5777-5782
Mitchell S (1993) Fire performance of wood: Test methods and fire retardant treatments. In: Proceedings of the 4th Annual BCC Conference on Flame Retardancy, 18-20 May, Stamford, CT. Business Communications Co. Norwalk, CT

SAS Institute Inc. (1994) Statistical Analysis Software for Microcomputer. SAS Institute Inc., Cary, NC

Wladyka-Przbylak M, Kozlowski R (1999) The thermal characteristics of different intumescent coatings. Fire Mater 23:33-43 